\title{
SCIENCE
}

NEW YORK, OCTOBER 28, 189.

\section{THE HUMMING-BIRD'S FOOD.}

BY MORRIS GIBBS, M D.

This article refers to the ruby-throat, the only representative of this interesting family in our State. Much has been written regarding the food of this species, and yet $I$ am satisfied that but few accurate notes have been offered to the readers. The writer offers observations taken with a view to learning of the feeding habits, and does not pretend to assert that others' notes, however conflicting, are not correct. Locality has everything to do with the habits of birds, and the requirements of the same species may differ vastly in a slight variation, either in latitude or longitude. Again, the resources of a region may radically alter the food habits of any and all animals. Certain it is, that my observations convince me, contrary to all writings that $I$ have seen, that the food of the ruby-throated humming-bird is mainly honey, and that these little fellows do not rely to any extent on an insect diet.

Years ago I captured several in our flower-garden with my insect net, and, in accordance with the views of all books read, they were offered insects as food, but invariably completely ignored everything of this nature set before them. No matter whether I gave them the liberty of a large room or confined the frightened creatures in my hand or a small box, the result was invariably the same; all insect food was refused, whether small beetles, or even those minute flies or gnats, often common about honey-producing flowers. However, on releasing the captive, it would immediately visit the flowers, and appear to revel in the exploration of the deep recesses of the fuchsias and trumpetcreepers. One immature specimen that I caught would sip sugar-water from my hand, and even protrude its delicate tongue for the sweets to be so easily had. This young one was so very unsophisticated that it had to be taught regarding the honey-water, by dipping its tiny, slender beak into the sticky mass, after which it quickly learned. The old ones only fluttered in my hand, and would not eat, but would apparently enjoy that which was forced into their bills. But, left to themselves and watched secretly, they could be seen indulging in the sweets provided for them. If held carefully and an insect forced between their mandibles, they invariably ejected it with a snap of the bill and a side jerk of the head.

Of the wild flowers of Michigan, there are many species which the hummers risit regularly, but as nearly all of these flowers are so far from my residence, it follows that my observations are mainly made from our house-plants and garden flowers. Of all of the uncultivated species that I know, the flowers of the wild crab-apple are most sought after by the ruby-throat, and during the season, about the middle of May, a hundred birds may be seen in a few hours about a group of these trees. There are very few insects on the crabs, and in wet days none, and yet the hummers swarm about. They must come alone for sweets. One point in relation to my theory of the hummer's love for honey would seem to receive a challenge, and it is, that the ruby-throat rarely hovers over the conmon red and white clover. Now, as we know, red clover is one of the sweetest of flowers, and a head is agreeable to anyone's palate, while the white clover is a great favorite with the honey-bee. My reply to this is, that the individual flower is too small for the ruby-throat's attention.

On our piazza in the city are a number of house-plants, some growing in a hanging-box, others in pots on a stand, while several species of out door perennials and annuals flourish in a bed just below, and a large creeper clambers near. It is safe to say that from early morning till evening twilight there will be an average of one visit every half-hour by the hummers to this collection. So unsuspicious have they become that one can study them at a yard's distance. One advantage in observing them is that they always make their presence known by their pleasant humming and a faint, sharp chirp; thus warning one when to lay aside the book and watch their movements.

On first appearing, they immediately dash towards the fuchsias, which are their greatest attraction, and the next best is the trumpet-creeper, and then the selection appears to them indifferent, as the pelargoniums, nasturtiums, morning-glories, and others are visited indiscriminately. However, the fuchsias are first choice, and, wondering at their preference, I examined the blossoms thoroughly for insects and sweets. In very few cases, and at rare intervals, I und small insects, as no others can reach the heart of the flower; but in every case I met with a most refreshing nectar, - to be sure, in very small quantity to us, but to a hummer, a most plentiful supply. Let my readers pluck a full-blown fuchsia blossom, and cutting into the calyx near the stem end, apply the part to the tip of the tongue, and they will be fully convinced why the hummer is partial to this beautiful pendant flower.

Thinking to test their fondness for sugar, some was dissolved and then dropped deeply into the blossoms of the creeper. In the course of the hour, in their rounds, the busy birds found the bait, and fully thrice the amount of time was spent on the extrasweetened flowers as was occupied over those of nature's honeying. The sweetening attracted many insects in the course of the day, principally ants and small flies and gnats, but not one instance of their capture could I detect, although careful record of the number of insects in each flower was kept, and the flower examined after each bird departed.

The movements of the hummers when visiting a bed of flowers are interesting. With a dash it is among us with the characteristic impetuosity of its kind, but it is not then detected by the ear, as the noise of a flying bird is but slight and not always heard. It is when the bright, red-throated fellow stops in mid-air that we hear his rapidly-vibrating wings, always loudest when he makes a sudden side-movement from flower to flower. Selecting a flower, after a second's inspection of his surroundings, a rush is made toward it at a very rapid rate, but just as we think he will fly past or against the blossom, he stops-stops instantly. In the fraction of a second he introduces his tiny, but long, slim bill into the heart of the flower, and then is away to the next. The swiftness with which this delicate bird travels about, exploring hundreds of flowers each hour of the day, and from:early morning till twilight is truly a marvel.

At each insertion of the tiny beak, his mobile tongue"is"thrust out and from side to side, and the sweets, and, I think, some pol. len, are drawn into its mouth. The tip of the tongue is peculiarly and beautifully constructed for this purpose, and with the perfect adaptability of its slender, delicate bill, the bird is endowed with the means of securing sweets, possessed by no other group of birds.

In conclusion, I will say that I have carefully dissected many humming-birds, both old and young, but have never found anything to convince me that the birds lived on insects. It may be that at times when flowers are scarce some species of insects are captured, but I am satisfied that in season, when flowers are abundant, that the ruby-throat of Michigan lives on honey.

Kalamazoo, Michigan. 